\title{
Considerations on the Right of Way as Cause of Road Accidents in Romania
}

\author{
Lucian Tarnu ${ }^{1}$, and Cristian Deac ${ }^{1, *}$ \\ ${ }^{1}$ Lucian Blaga University of Sibiu, Romania, Department of Industrial Engineering and Management, Emil Cioran str., 4, Sibiu, \\ Romania
}

\begin{abstract}
While cars and road traffic are an essential component of modern human society, the accidents that may occur in traffic are one of the largest sources of deaths and injuries. A first important step towards reducing these road accidents is the identification of their main causes. In the the current paper, the authors analyse the main causes of road accidents in Romania and then discuss the conditions surrounding the accidents that had as cause the failure to properly grant right of way, taking into account both the national, regional (county-level) and local statistics.
\end{abstract}

\section{Introduction}

Road transportation is one of the most common expressions of modern civilisation. On the one hand, cars make it possible to move between various locations in a much shorter time than it was possible 200 years ago and on the other hand they can represent powerful status symbols.

However, the popularity of this means of transportation has led in many places to very busy roads. Moreover, the increase in the number of cars driving on roads and motorways has led in many countries and regions also to an increase in the number of car accidents. Fatal car accidents are especially tragic and costly, both in terms of the material losses and in terms of human lives, representing a major problem of the human society.

Statistics at world level [1] show that in 2012 road traffic injuries were the main cause of death for the age group 15-29 years (Fig. 1 [1]) and it is projected to be ranked $7^{\text {th }}$ among all age groups in 2030. This situation is worse than that recorded for 2002 [2], when it was reported that road traffic injuries were the second-mostfrequent cause of death for the age groups 5-14 years and 15-29 years and the third-most frequent cause of death for the age group 30-44 years. On the other hand, the number of road deaths seems to have remained at roughly the same level from 2007 to 2013 - 1.25 million deaths worldwide [1].

The European Union is the safest world region in this regard, mainly due to ambitious goals set in this regard by the European Commission. While the target set in 2001 for 2010 - a $50 \%$ reduction of road traffic fatalities - has not been fully reached (the reduction was of only 35\%), these targets were renewed in the White Paper on Transport and the Action Programme on Road Safety for the period from 2011 to 2020 , even aiming towards a rate of zero road traffic fatalities in 2050. [3]

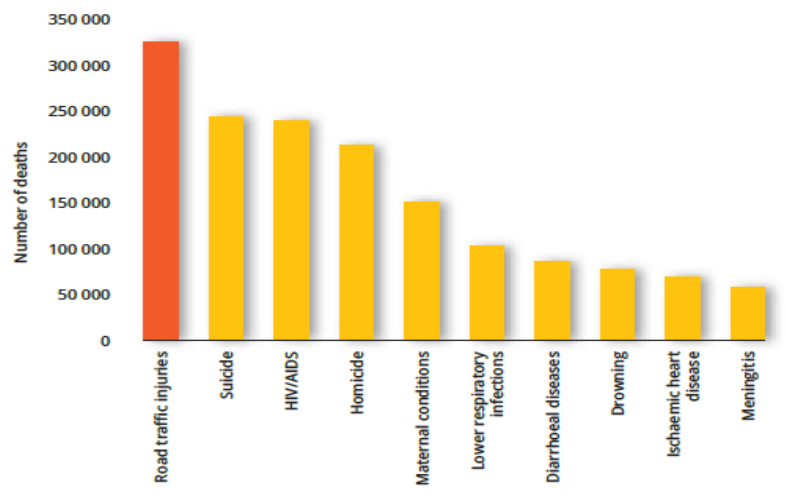

Fig. 1. The main causes of death for people in the age group 1529 years, at world level, in 2012 [1]

One of the main conditions for achieving these ambitious goals is to precisely identify the causes that can lead to road accidents and especially to road fatalities and to develop corresponding measures for combatting them.

In the current paper, the authors analyse the main causes of road accidents in Romania and especially the failure to properly yield the right of way as one of the main causes, suggesting a series of measures that need to be implemented, both at national, regional and local level in order to help reduce the number of accidents that have this cause.

\section{Road Accidents - Situation and Main Causes at World Level and in Romania}

Since their invention at the end of the $19^{\text {th }}$ century, cars have gradually transformed and improved human life, they imposed an accelerated rhythm, shortened travel distances and durations and became one of the symbols of modern civilisation. [4] 
Across the European Union, the number of passenger cars grew by $4.5 \%$ over the last five years, from 241 to 252 million [5]

In Romania, cars first appeared very soon after this means of transportation was invented, more precisely around the year 1890. Currently, there are around 5.7 million cars registered in Romania and more than 6.6 million persons have driver's licenses. [4]

Unfortunately, car traffic is sometimes accompanied by accidents that lead each year to important material damage, to minor or major injuries or even the death of participants in the road traffic: car drivers, pedestrians, passengers, bicycle riders, motorcycle riders etc. [4] Statistics at world level show that each year, 1.2-1.5 million people die in car accidents, most of whom are young people, while other 35 million people receive severe or light injuries. [1] An accident-caused fatality is a family tragedy, but represents also a significant loss for the whole society, given the efforts undertaken for the education, professional training and training for life of the young generations. [4]

Because road vehicles are a favourite way for people to commute to and from the workplace or to carry out their daily jobs, road traffic accidents can be regarded as work accidents, so risks related to road safety can be determined with a methodology similar to that used for determining the risks at the workplace. [5]

In recent years, road safety has become a major topic for many governments and administrative institutions, including at the level of the European Union. The road safety policy of the European Union aims to increase the road safety level so as to allow the safe and ecological movement of citizens on all roads of the member states. It promotes the equality of all road traffic participants and for this seeks to increase the road safety level for the most vulnerable among them. $[3,6,7]$

The European Commission considers following three actions as having paramount importance in the area of road safety $[3,8]$ :

- Implementing a structured and coherent cooperation framework based on the best practices in the member countries, as a necessary condition for efficiently implementing the orientations for the European road safety policy 2011-2020;

- Elaborating a strategy regarding injuries and granting first aid, in order to answer the more and more acute need to reduce the number of road accidents leading to injuries;

- Increasing the safety of vulnerable participants in the road traffic, especially with regard to motorcycle riders, in whose case statistics are worrying.

A study published by the World Health Organisation in 2015 [1] has found that the main risk factors and causes for road accidents are the following ones:

- Excessive and/or inadequate speed;

- Risky/reckless behaviour by pedestrians and cyclists;

- Poor road engineering works;

- Poor state of the cars/vehicles.
- Inexperience, thrill-seeking and low alcohol tolerance of (especially young) drivers and riders;

One way to systematise the main causes and to aid in elaborating more efficient measures to combat them is the so-called Haddon matrix (Fig. 2 [9]), used either in the simplified form presented or in expanded forms as base for proactive initiatives.

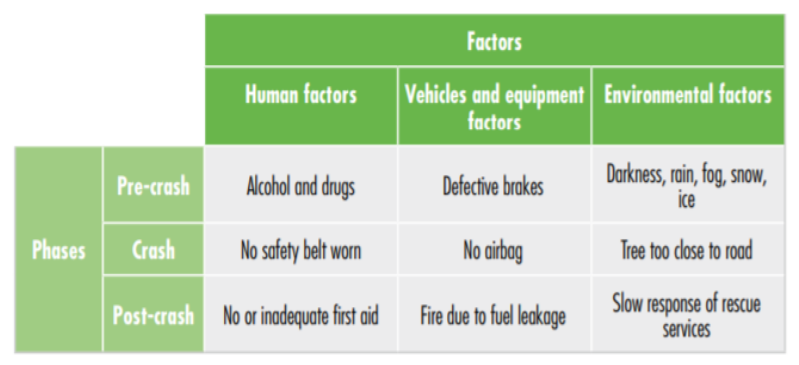

Fig. 2. Haddon matrix [9]

The main causes of road accidents in Romania include $[6,10,11]$ :

- Offenses by pedestrians;

- Inadequate speed;

- Failure to yield right of way to vehicles;

- Failure to yield right of way to pedestrians;

- Failure to maintain an adequate distance between vehicles;

- Offenses by bicycle riders;

- Reckless driving;

- Irregular overtaking manoeuvres;

- Driving under the influence of alcohol;

- Inadequate manoeuvres to switch lanes.

Between 2005 and 2012, in Romania there were reported 252633 road accidents, the causes of which were distributed as indicated in Fig. 3 (data from [12]).
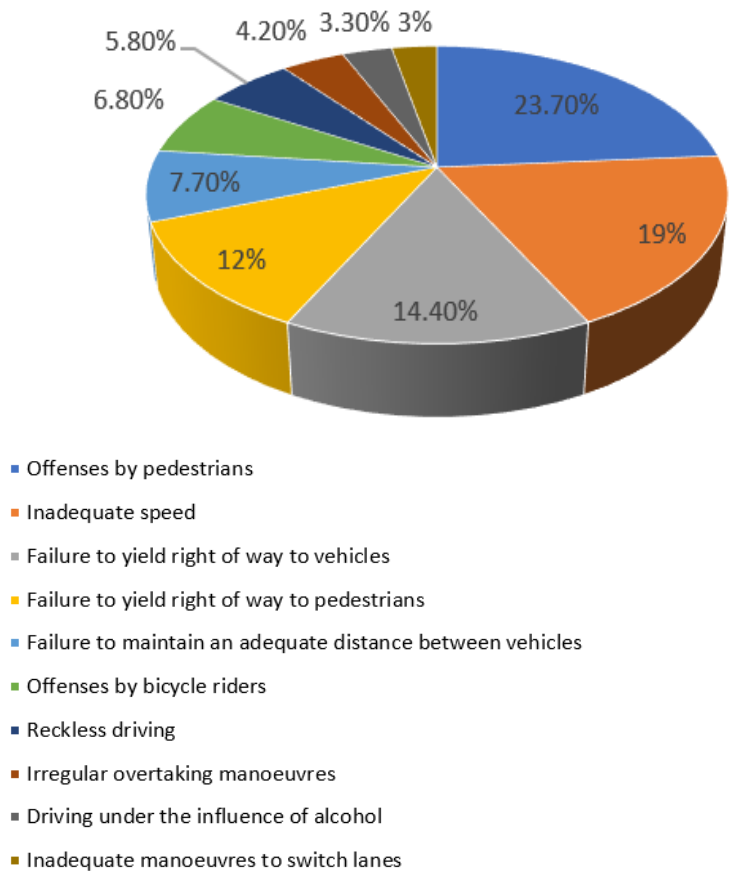

Fig. 3. Weight of the main causes of road accidents in Romania between 2005 and 2016 [12] 


\section{Analysis of number of accidents caused by the failure to yield right of way to other vehicles in Romania}

In Romania, the Inspectorate General of the Romanian Police is the authority mandated to collect and manage the data referring to road accidents. It can then transmit the data to the National Statistics Institute and to the interested international institutions.

For their analysis, the authors resorted to data retrieved from the National Registry of Car Accidents [12].

As can be seen from Fig. 3, the failure to yield right of way to vehicles is one of the most important causes for road accidents in Romania.

The number of accidents and the number of victims stemming from the failure to properly yield right of way to vehicles in Romania, in the years 2007-2016, is shown in Fig.s 2 and 3, respectively. In all, between 2007 and 2016 there were reported 32252 accidents that led to 46739 victims (fatalities, severe injuries or light injuries).

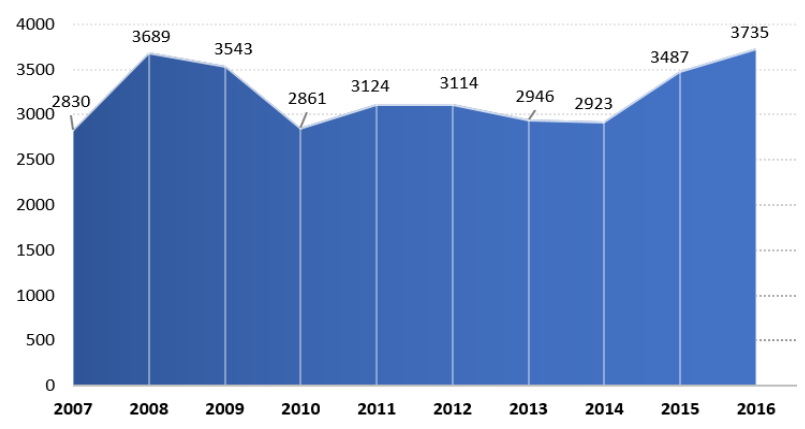

Fig. 4. Evolution of the number of road accidents caused by the failure to yield right of way to vehicles, between 2007 and 2016, in Romania.

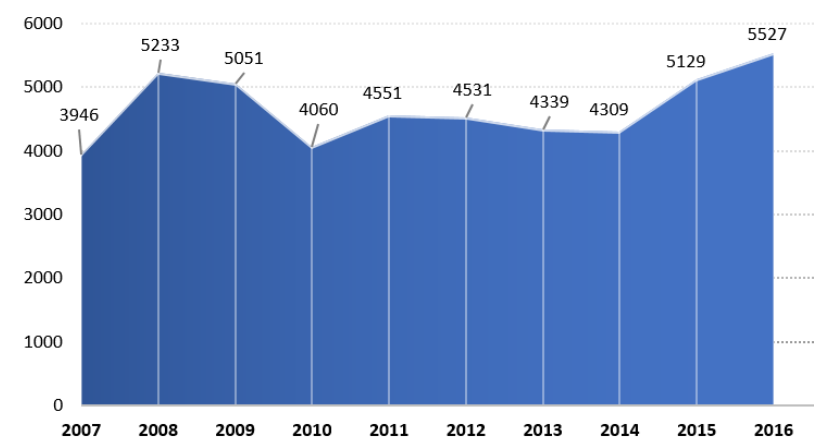

Fig. 5. Evolution of the number of victims of road accidents having as cause the failure to yield right of way to vehicles, between 2007 and 2016, in Romania.

Table 1 presents the evolution of the number of fatalities, of severe injuries and of light injuries in the period between 2007 and 2016.

From these Fig.s it can be seen that, while the numbers have fluctuated from year to year, overall the number of accidents caused by the failure to yield right of way to other vehicles has increased. However, the increase is largely due to the increase in the number of light injuries, while the number of fatalities has decreased.
Table 1. Evolution of the number of fatalities, severe injuries and light injuries in accidents having as main cause the failure to yield right of way.

\begin{tabular}{|l|l|l|l|}
\hline Year & $\begin{array}{c}\text { Number of } \\
\text { fatalities }\end{array}$ & $\begin{array}{c}\text { Number of } \\
\text { severe } \\
\text { injuries }\end{array}$ & $\begin{array}{c}\text { Number of } \\
\text { light injuries }\end{array}$ \\
\hline 2007 & 152 & 666 & 3128 \\
\hline 2008 & 132 & 905 & 4196 \\
\hline 2009 & 129 & 874 & 4048 \\
\hline 2010 & 95 & 753 & 3212 \\
\hline 2011 & 108 & 780 & 3663 \\
\hline 2012 & 87 & 841 & 3603 \\
\hline 2013 & 61 & 724 & 3554 \\
\hline 2014 & 69 & 658 & 3582 \\
\hline 2015 & 83 & 910 & 4199 \\
\hline 2016 & 66 & 663 & 4798 \\
\hline Total & 982 & 7774 & 37983 \\
\hline
\end{tabular}

A county-level analysis reveals an average number of 768 accidents caused by failure to yield right of way per county from 2007 to 2016. However, this average is misleading, since the county-level municipality of Bucharest recorded a much higher number of accidents than any other county (7424). Furthermore, as can be seen from Fig. 1, several other counties - Constanta, Timis, Ilfov, Prahova, Cluj - reported figures above the average, while others - Vaslui, Covasna, Salaj, Tulcea, BistritaNasaud - remained well below this average.

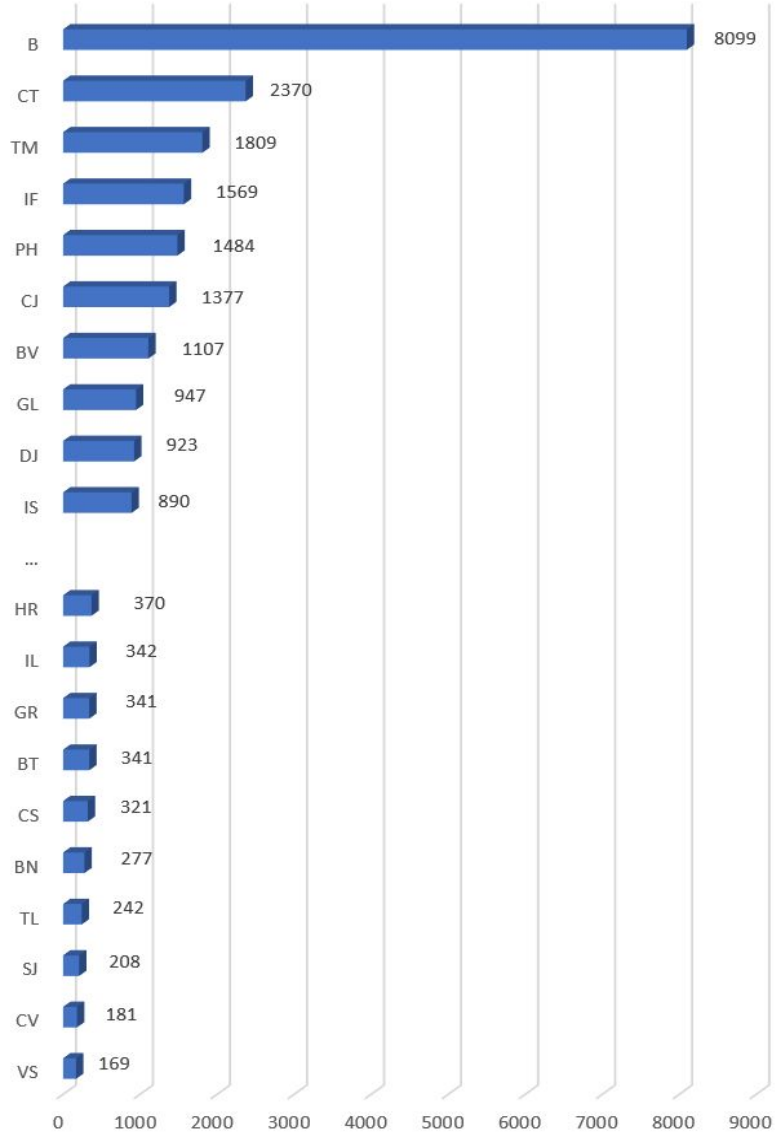

Fig. 6. Number of accidents caused by the failure to yield right of way to vehicles, by county, between 2005 and 2017 
The vast majority (91\%) of the total number of accidents took place within the limits of settlements and only a small part can be ascribed to the higher speeds allowed outside of settlements.

Also, $75 \%$ of the accidents were lateral (sideways) collisions, $15 \%$ were frontal collisions, $6 \%$ were due to tailgating and $4 \%$ were other types of collisions, such as chain collisions (Fig. 7).

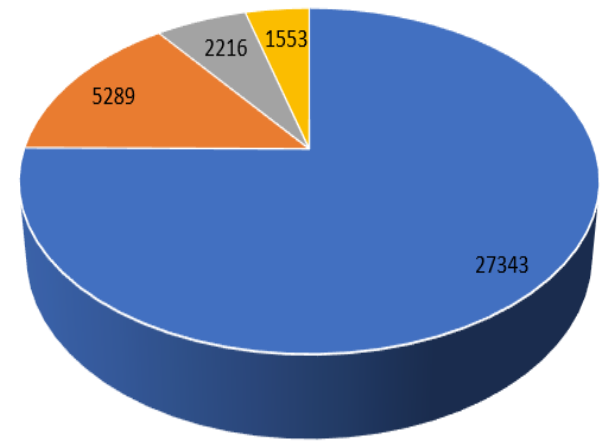

- lateral collisions | frontal collisions | tailgating " other types of collisions

Fig. 7. Number of accidents caused by the failure to yield right of way by vehicles grouped by the type of collision.

\section{Measures for the reduction of the number of accidents caused by the failure to yield right of way to other vehicles in Romania}

As a conclusion of the analysis presented in the previous paragraph and in agreement with the speciality literature in this area, following measures can be considered in order to reduce the number of accidents that have this cause:

- Dissemination of information on road education issues and on road safety campaigns;

- Firm attitude of the policemen towards any infringements of the law on the roads;

- Periodic checking of the technical status of the vehicles and of the legality of the transportation activities carried out;

- Improvement of the cooperation between the various actors involved in road works for a better direction of traffic in those areas and for the provision of a larger area of visibility around crossroads;

- Periodic checking and improvement of the traffic signs and other signalling devices (placing them in more visible positions, increasing their reflectivity at night etc.), especially with regard to the right of way signs and in the areas with potentially dangerous crossroads or curves;

- Installation of more video surveillance equipment and eventually the implementation of an intelligent road traffic monitoring system;

- Meetings between road traffic participants on road safety topics;
- Improvement of the attitude of passenger car drivers towards pedestrians, public transportation drivers, bicycle and motorcycle riders etc.

\section{Conclusions}

Road safety is an issue of interest for all citizens, each of them being able to contribute to increasing the safety of traffic on public roads.

As the current paper has shown, the failure to yield right of way to vehicles is an important cause of road accidents, at world level and in Romania, even if the numbers vary significantly between the various areas and counties.

A thorough implementation of the measures suggested in the paper would certainly lead to a significant reduction in the number of accidents with this cause.

In future, the authors intend to extend their researches also to other causes of road accidents and by applying a questionnaire on road safety to the various categories of participants in the road traffic, especially in the identified problem areas.

\section{References}

1. World Health Organization, Global status report on road safety 2015 (World Health Organization, 2015)

2. M. Peden, World report on road traffic injury prevention (World Health Organization, Geneva, 2004)

3. European Commission, White Paper on Transport (European Commission, 2011)

4. L.I. Tarnu, Analysis, investigation and reconstruction of road accidents (Translated from Romanian) (Publishing House Universul Juridic, Bucharest, 2012)

5. A. Gligor, Bull. Univ. Ploiesti, LXVI, 4 (2015)

6. L.I. Tarnu, Investigation and reconstruction of road accidents (Translated from Romanian) (Publishing House of the "Lucian Blaga" University of Sibiu, Sibiu, 2009)

7. ETSC, $4^{\text {th }}$ PIN Report: Road Safety Target in Sight: Making up for Lost Time (ETSC, 2010)

8. L.I. Tarnu, Aspects of the systematisation and signaling of road traffic in Romania (Translated from Romanian) () (Publishing House of the "Lucian Blaga" University of Sibiu, Sibiu, 2016)

9. DEKRA, Road Safety Report 2017 - Best Practices (DEKRA, 2017)

10. Inspectorate-General of the Romanian Police, Road Safety Bulletin. Annual Report 2016 (Romanian Police, 2017)

11. Government of Romania, Decision 755/2016 on the Approval of the National Strategy for Road Safety 2016-2020 (Official Monitor of Romania, 2016)

12. Inspectorate-General of the Romanian Police, National Registry of Road Accidents (Romanian Police, 2017) 